\title{
Peran Personal Development Competitive Attitude dan Organizational Citizenship Behavior terhadap Manajemen Konflik pada Karyawan Event Organizer
}

\author{
Natalie Puspita*l \\ Fakultas Psikologi Universitas Ciputra \\ Jimmy Ellya Kurniawan \\ Fakultas Psikologi Universitas Ciputra
}

\begin{abstract}
The dynamic phenomenon of EO requires collaboration between members to run events, especially when facing conflicts that arise. The collaborative conflict management style can be referred to as a solutionorientation conflict management. In connection with this phenomenon, personal development competitive attitude and organizational citizenship behavior is known to play a role in improving conflict management solution-orientation among EO employees. This research is a quantitative study with multiple regression design. The population of this study were event organizer employees in Surabaya. The sample in this study amounted to 114 event organizer employees obtained through online surveys. The sampling technique used accidental sampling. This study uses a personal development competitive attitude scale (PDCA) designed by Ryckman et al. (1996), Organizational Citizenship Behavior Scale (OCB) designed by Podsakoff et al. (1990), and the Organizational Communication Conflict Instrument (OCCI) designed by Putnam et al. (1982). The results of hypothesis testing state the role of personal development competitive attitude and organizational citizenship behavior in conflict management solution-orientation. In this study the variable organizational citizenship behavior has a bigger role than personal development competitive attitude. The results of the research can be used as knowledge and input for the company and EO employees.
\end{abstract}

Keywords: personal development competitive attitude, organizational citizenship behavior, solution- oriented conflict management

\begin{abstract}
Abstrak. Fenomena dinamika EO membutuhkan kolaborasi antar anggota untuk menjalankan acara terutama saat menghadapi konflik yang muncul. Gaya manajemen konflik kolaborasi dapat disebut sebagai manajemen konflik solution-orientation. Berkaitan dengan fenomena tersebut, personal development competitive attitude dan organizational citizenship behavior diketahui berperan dalam meningkatkan manajemen konflik solutionorientation pada karyawan EO. Penelitian ini merupakan penelitian kuantitatif dengan desain regresi berganda. Populasi dari penelitian ini adalah karyawan event organizer di Surabaya. Sampel dalam penelitian ini berjumlah 114 karyawan event organizer yang diperoleh melalui survei online. Teknik pengambilan sampel dilakukan dengan teknik accidental sampling. Penelitian ini menggunakan personal development competitive attitude scale (PDCA) yang dirancang oleh Ryckman et al. (1996), Organizational Citizenship Behavior Scale (OCB) yang dirancang oleh Podsakoff et al. (1990), dan Organizational Communication Conflict Instrument (OCCI) yang dirancang oleh Putnam et al. (1982). Hasil uji hipotesis menyatakan adanya peran personal development competitive attitude dan organizational citizenship behavior pada manajemen konflik solutionorientation. Pada penelitian ini variabel organizational citizenship behavior memiliki peranan yang lebih besar dibandingkan personal development competitive attitude. Hasil penelitian dapat digunakan sebagai pengetahuan dan masukan bagi perusahaan dan karyawan EO.
\end{abstract}

Kata kunci :personal development competitive attitude, organizational citizenship behavior, manajemen konflik solution-orientation

\footnotetext{
${ }^{1}$ Korespondensi: Natalie Puspita. Fakultas Psikologi Universitas Ciputra Surabaya, UC Town, Citraland, Surabaya, 60219. Email: nataliepuspita1@gmail.com
} 
Sumber daya manusia pada perusahaan EO identik dengan tingginya turnover karyawan (Dalimunthe et al., 2017). Hal tersebut tidak lepas dari kepuasan kerja karyawan yang rendah. Kondisi kerja yang memiliki tuntutan yang beragam di suatu waktu dapat membuat tekanan bagi para karyawan EO sehingga dapat mengganggu kepuasan kerja dan menjadi penyebab utama turnover karyawan EO. Fenomena lain terkait konflik dalam perusahaan EO yaitu, berawal dari konflik internal suatu perusahaan EO yang berujung pada penculikan dan penyekapan pada tahun 2015 di Jakarta (Manurung, 2020). Kedua pihak yaitu, korban maupun tersangka adalah rekan kerja dalam perusahaan EO yang sama. Konflik yang muncul berawal dari masalah keuangan. Hal ini membuktikan bahwa ketika konflik tidak mampu dikelola dan ditangani dengan baik, maka dapat berakibat pada tindakan kekerasan. Selain membawa dampak yang buruk pada diri karyawan, Widiyanto (2018) berpendapat bahwa konflik yang muncul antar karyawan dalam suatu perusahaan akan membawa dampak negatif bagi kinerja perusahaan seperti memunculkan kondisi yang tidak kondusif saat bekerja dan menghambat kinerja perusahaan. Dampak negatif yang dialami karyawan saat mengalami konflik dengan rekan kerja dirasakan sebagai suatu tekanan sehingga dapat mengganggu kesehatan fisik maupun mental (Kompas, 2020). Hal tersebut juga mengakibatkan kerugian bagi perusahaan karena sumber daya manusianya tidak dapat bekerja secara optimal dikarenakan stres yang berkepanjangan dan dapat membuat karyawan rentan sakit secara fisik. Apabila ditinjau dari segi psikis, pada karyawan yang merasa tidak aman dengan lingkungan kerjanya, terbukti mengalami kondisi psikis yang kurang baik (Rusdiana, 2015). Ketika karyawan merasa tidak aman dan nyaman dalam lingkup kerjanya seringkali karyawan tersebut berakhir dengan keluar dari pekerjaan. Hal ini selaras dengan pernyataan Dalimunthe et al. (2017) bahwa relasi antar rekan kerja yang terganggu akan berdampak pada kepuasan kerja rendah dan berakhir pada turn over.

Timbulnya konflik dari berbagai penyebab dalam kinerja EO menjadi hal yang perlu diperhatikan dikarenakan kerja tim sangat dibutuhkan untuk kesuksesan acara yang ditangani. Hal ini dikuatkan oleh pernyataan dari Larson (2001) bahwa perusahaan jasa seperti, EO keberlangsungannya sangat bergantung pada keterlibatan anggota tim itu sendiri dalam penyelesaian tugas meskipun banyak muncul konflik dalam relasi interpersonalnya. Tanpa penanganan konflik yang tepat produktivitas perusahaan akan terganggu. Hal ini akan sangat mengganggu kinerja tim EO secara keseluruhan sehingga dibutuhkan manajemen konflik yang sesuai.

Manajemen konflik menurut Putnam dan Wilson (1982) dijelaskan sebagai strategi komunikasi yang digunakan individu dalam menangani konflik. Strategi komunikasi yang dimaksud berupa verbal dan non-verbal. Dalam menghadapi suatu konflik tidak dapat ditentukan cara terbaik dalam menangani konflik. Hal tersebut sesuai dengan pernyataan Putnam dan Wilson (1982) bahwa tidak ada strategi komunikasi yang paling baik untuk dijadikan suatu pedoman dalam strategi komunikasi saat menangani konflik. Dalam penanganan suatu konflik perlu melihat beberapa hal misalnya karakter dari pihak yang terlibat konflik sehingga tidak dapat dipastikan satu cara yang terbaik dalam menangani konflik. Pada penelitian ini lebih difokuskan kepada teori manajemen konflik solutionorientation yang dipaparkan oleh Putnam dan Wilson (1982).

Pada penelitian ini fokus pada manajemen konflik solution-orientation yang didasarkan pada fenomena dinamika EO yang membutuhkan kolaborasi antar 
anggota untuk menjalankan acara. Hal tersebut sangat penting dimiliki terutama saat menghadapi konflik yang timbul. Cara dalam mengatasi konflik yang mengarah pada manajemen konflik solutionorientation seperti mengintegrasikan berbagai ide kreatif diskusi, bahkan berkompromi dengan pihak lawan sehingga tidak ada pihak yang lebih dominan untuk memaksakan ide (Putnam \& Wilson, 1982). Manajemen konflik yang individu lakukan pada dasarnya berasal dari kehendak individu itu sendiri yang juga dipengaruhi oleh faktor internal yang dibawa oleh masing masing individu.

Faktor-faktor yang mempengaruhi manajemen konflik diantaranya adalah asumsi mengenai konflik, persepsi terhadap penyebab konflik, ekspektasi reaksi dari lawan konflik, pola komunikasi dalam interaksi konflik, kecerdasan emosional, kepribadian. Dengan adanya perbedaan yang dibawa oleh masingmasing individu yang bisa saja menjadi faktor munculnya konflik, maka tentu saja pemaknaan terhadap suatu konflik pada setiap individu bisa berbeda sehingga penelitian ini akan berfokus pada faktor internal individu yaitu personal development competitive attitude dan organizational citizenship behavior.

Ryckman, Hammer, Kaczor, dan Gold (1996) mendefinisikan personal development competitive attitude sebagai pengembangan personal untuk sukses dan menikmati tantangan yang ada namun tetap berfokus pada pertumbuhan pribadi tanpa membandingkan dengan orang lain. Individu dapat melihat peluang bahwa dengan adanya konflik justru dapat membuat dirinya lebih dapat berkembang dan bertumbuh (self-improvement) serta mampu menghadapi konflik dengan perasaan tenang dan aman. Dengan demikian tidak selamanya tantangan menghasilkan suatu yang negatif bagi individu. Bisa saja dengan adanya konflik yang dipandang sebagai suatu hal yang menantang bagi diri membuat karyawan termotivasi untuk memenangkan tantangan tersebut secara sehat (Rusdiana, 2015). Sebaliknya dari hypercompetitive, individu lebih cenderung kepada pengembangan diri yaitu dengan menunjukkan perilaku agresif, manipulasi, eksploitasi, dan merendahkan orang lain (Ryckman, Hammer, Kaczor, dan Gold, 1990).

Dinamika konflik karyawan EO secara garis besar bersamaan dengan adanya kesalahan komunikasi. Anwar (2015) menjelaskan bahwa salah satu penyebab komunikasi yang terhambat adalah adanya perilaku yang buruk dari karyawan. Perilaku buruk tersebut seperti adanya ancaman, intimidasi, atau penyampaian informasi yang kurang benar. Dengan adanya konflik berupa komunikasi pada relasi antar karyawan maka sikap dari karyawan sangat menentukan bagaimana kesuksesan pekerjaan tersebut. Dengan demikian penting untuk setiap karyawan menunjukan perilaku yang positif baik bagi dirinya dan kinerja perusahaan.

\section{Organizational Citizenship Behavior} (OCB) membahas mengenai perilaku individu dalam suatu organisasi yang tidak diatur secara formal, namun dapat menunjang efektivitas perusahaan (Podsakoff, MacKenzie, Moorman, \& Fetter, 1990). Dapat dikatakan bahwa OCB menggambarkan perilaku individu yang bekerja melebihi peran formal yang dikerjakan dalam suatu organisasi. Pada penelitian ini, individu yang dimaksud adalah karyawan EO. Ketika karyawan memberikan kinerja yang melebihi peran formalnya dapat dikatakan memiliki OCB yang tinggi. OCB sering digunakan untuk melihat perilaku karyawan sebagai standar pengukuran untuk pertimbangan evaluasi kinerja karyawan meskipun tidak diukur secara formal.

Organ (dalam Lievens \& Anseel, 2004) menyatakan terdapat perilaku-perilaku yang menggambarkan OCB seperti 
altruism,

conscientiousness, sportsmanship, courtesy, dan civic virtue. Altruism merupakan perilaku karyawan membantu orang lain secara spesifik dalam tugas yang berkaitan dengan organisasinya. Conscientiousness merupakan perilaku yang dimunculkan karyawan dalam hal melakukan kinerja lebih dari batas minimum perusahaan. Sportmanship adalah perilaku karyawan untuk mampu menoleransi perubahan yang terjadi di bawah standar tanpa komplain. Courtesy merupakan perilaku karyawan yang ditujukan untuk mencegah munculnya masalah yang berkaitan dengan pekerjaan. Civic virtue merupakan partisipasi dan perhatian individu terhadap keberlanjutan perusahaan. Dapat dilihat bahwa ada fenomena perilaku yang melebihi peran formal yang ditunjukkan antarkaryawan dengan tujuan agar acara tetap bisa berjalan maksimal. Hal tersebut menggambarkan sikap yang termasuk dalam OCB kepada sesama karyawan agar tujuan bersama tercapai dengan cara saling membantu satu sama lain. Hanya saja dalam penelitian ini sikap yang merepresentasikan OCB akan dilihat lebih terperinci dalam lima dimensi.

Penelitian terdahulu menemukan bahwa tipe manajemen konflik dari individu dapat berbeda-beda karena dipengaruhi oleh faktor kepribadian maupun lingkungan sosial individu. Hal ini cukup menjadi referensi bagaimana tipe manajemen konflik pada individu terbentuk. Penelitian spesifik terkait personal development competitive attitude dan organizational behavior citizenship pada manajemen konflik solution- orientation belum pernah dilakukan. Hal ini menjadi suatu yang menarik untuk ditinjau terutama pada subjek karyawan EO. Pemilihan subjek penelitian pada karyawan event organizer menjadi sesuatu yang unik dalam penelitian ini dikarenakan perusahaan event organizer mengharuskan interaksi yang cukup intens antar karyawan dalam penyelenggaraan acara. Perbedaan pandangan, pendapat, hingga permasalahan yang muncul merupakan hal yang wajar terjadi. Hal tersebut menjadi dasar bahwa kemampuan manajemen konflik solution-orientation penting untuk dimiliki agar konflik yang terjadi dapat diatasi dan menguntungkan perusahaan. Dengan demikian manajemen konflik solution-orientation yang ada pada karyawan event organizer cukup menarik dan penting untuk diteliti.

\section{TUJUAN PENELITIAN}

Mengetahui peran personal development competitive attitude dan organizational citizenship behavior terhadap manajemen konflik solution - orientation pada karyawan EO.

\section{HIPOTESIS}

Terdapat peran personal development competitive attitude dan organizational citizenship behavior terhadap manajemen konflik solution orientation pada karyawan EO.

H1: Mengetahui peran personal development competitive attitude terhadap manajemen konflik solution-orientation pada karyawan EO.

H2: Mengetahui peran organizational citizenship behavior terhadap manajemen konflik solution-orientation pada karyawan EO.

\section{METODE}

Penelitian ini merupakan penelitian kuantitatif dengan desain regresi berganda. Arikunto (2013) menyatakan analisis dengan menggunakan regresi berganda ditujukan untuk melihat sejauh mana hubungan satu variabel terikat dengan dua atau lebih variabel bebas. Penelitian ini bertujuan untuk mengetahui peran personal development competitive attitudes dan organizational citizenship 
behavior terhadap manajemen konflik solution-orientation pada karyawan EO. Analisis korelasi dalam penelitian ini menggunakan bantuan program software JASP 0.9.2. Teknik sampling yang digunakan pada penelitian ini menggunakan accidental sampling accidental sampling yang merupakan salah satu dari non-probability sampling. Menurut Sugiyono (dalam Sulistyaningrum, 2012) mendefinisikan accidental sampling sebagai teknik pengambilan sampel yang dilakukan oleh peneliti kepada subjek yang ditemui selama memenuhi karakteristik populasi yang ditentukan sebagai sumber data. Kumpulan data responden diseleksi pada tahap akhir berdasarkan kecocokan sampel penelitian. Jumlah sampel pada penelitian ini adalah 114 karyawan EO.

\section{Manajemen Konflik Solution- Orientation}

Pada penelitian ini, skala manajemen konflik solution-orientation yang digunakan adalah Organizational Communication Conflict Instrument (OCCI) yang dirancang oleh Putnam dan Wilson (1982) berupa skala likert. Alat ukur ini bersifat unidimensional. Skala ini dibuat berupa likert terdiri dari 11 aitem favorable. Skor satu menunjukkan (tidak pernah) hingga tujuh (selalu). Semakin tinggi skor total mengartikan bahwa individu memiliki frekuensi yang tinggi pada manajemen konflik solutionorientation dan sebaliknya. Putnam dan Wilson (1982) melakukan uji skala terhadap skala OCCI. Nilai koefisien alpha skala OCCI solution orientation sebesar 0.88 dengan rentang item total correlations 0.51-0.66. Pada penelitian ini melalui hasil pengujian skala terdapat aitem yang gugur yaitu aitem nomor empat dikarenakan item rest correlation dibawah 0,3. Melalui pengguguran tersebut didapatkan 10 aitem yang memiliki rentang Item-Rest Correlation sebesar
0,448-0,735 dan Alpha Cronbach sebesar 0,893 .

\section{Personal Development Competitive Attitude}

Penelitian ini menggunakan alat ukur personal development competitive attitude scale yang memiliki 15 aitem dan dirancang oleh Ryckman et al. (1996). Pada penelitian mengenai alat ukur dari Ryckman et al. (1996) memiliki nilai koefisien alpha sebesar 0.89 dengan rentang item total correlations $0.35-0.81$. Pada penelitian ini didapatkan hasil uji reliabilitas Personal Development Competitive Attitude, terdapat satu nomor yang harus digugurkan yaitu aitem nomor 11. Hal tersebut dikarenakan Item-Rest Correlation aitem nomor 11 dibawah 0,3. Melalui pengguguran tersebut didapatkan 14 aitem yang memiliki rentang Item-Rest Correlation sebesar 0,367-0,711 dan Alpha Cronbach sebesar 0,888.

\section{Organizational Citizenship Behavior}

Pada penelitian ini, skala organizational citizenship behavior yang digunakan oleh peneliti adalah Organizational Citizenship Behavior Scale yang dirancang oleh Podsakoff et al. (1990). Alat ukur ini bersifat multidimensional serta mengacu pada teori yang dikemukakan Organ (dalam Podsakoff et al., 1990). Organizational Citizenship Behavior adalah perilaku yang dimunculkan individu melebihi tugas yang telah ditetapkan yang dapat menunjang efektivitas perusahaan. Terdapat lima dimensi yaitu altruism (5 aitem), conscientiousness (5 aitem), courtesy (5 aitem), sportsmanship (5 aitem), dan civic virtue (4 aitem). Skala berupa likert dengan skor satu hingga tujuh. Skor satu (Sangat Tidak Setuju) hingga tujuh (Sangat Setuju). Semakin tinggi skor total yang didapatkan menunjukkan semakin kuat organizational citizenship behavior yang dimunculkan individu dan 
sebaliknya. Alat ukur tersebut memiliki nilai koefisien alpha sebesar 0.94 dengan rentang item- rest correlation $0.52-1.36$. Hasil uji reliabilitas Organizational Citizenship Behavior, terdapat satu nomor yang harus digugurkan yaitu aitem nomor 5. Hal tersebut dikarenakan Item- Rest Correlation aitem nomor 5. Melalui pengguguran tersebut didapatkan 23 aitem yang memiliki rentang Item-Rest Correlation sebesar 0,324-0,722 dengan Cronbach's Alpha di atas 0,6 pada semua dimensi.

\section{HASIL DAN DISKUSI}

Berdasarkan hasil uji yang telah dilakukan, diketahui bahwa terdapat peran personal development competitive attitude dan organizational citizenship behavior pada manajemen konflik dengan $\left(\mathrm{R}=598 ; \mathrm{R}^{2}=\right.$ $0,357 ; \mathrm{F}=30,83 ; \mathrm{p}<0,001)$. Hal tersebut diartikan bahwa dua variabel bebas memiliki peran yang signifikan sebesar $35,7 \%$ terhadap manajemen konflik solution-orientation. Pernyataan tersebut didukung oleh Basuki dan Prawoto (2016) menyatakan bahwa besarnya $\mathrm{R}^{2}$ mengartikan seberapa besarnya variabel bebas memberikan penjelasan variabel terikat.

Diketahui bahwa peranan organizational citizenship behavior $\left(\mathrm{R}=0,567 ; \mathrm{R}^{2}=\right.$ $0,322 ; \mathrm{t}=6,003 ; \mathrm{p}<0,001)$ lebih besar dibandingkan personal development competitive attitude pada manajemen konflik solution-orientation $\left(\mathrm{R}=0,031 ; \mathrm{R}^{2}\right.$ $=0,035 ; \mathrm{t}=2,478 ; \mathrm{p}=0,015)$. Hasil tersebut dapat ditinjau lebih dalam melalui definisi dari organizational citizenship behavior yaitu suatu perilaku individu dalam suatu organisasi yang tidak diatur secara formal, namun dapat menunjang efektivitas perusahaan. Organizational citizenship behavior memiliki lima dimensi yang dapat menunjukkan secara terbehavior berperan dalam mempertahankan fungsi perusahaan (Brahmasari, 2009). Perilaku tersebut dapat dimunculkan berupa usaha tolongmenolong yang dapat meningkatkan sinergi dalam suatu tim, usaha memelihara fungsi tim, dan aktif berpartisipasi dalam keseluruhan agenda termasuk penyelesaian konflik dengan rekan kerja. Putri dan Utami (2017) menyatakan bahwa dengan budaya organisasi yang terbangun seperti organizational citizenship behavior, akan memberikan suasana yang nyaman sehingga relasi antar karyawan tetap positif sekalipun terdapat konflik yang terjadi. Dengan adanya perilaku-perilaku tersebut, individu akan terbiasa berpartisipasi dalam menangani permasalahan atau konflik yang ada dalam lingkaran pekerjaannya. Hal ini yang membuat organizational citizenship behavior memiliki peranan yang besar terhadap manajemen konflik solutionorientation. perinci perilaku-perilaku yang muncul. Secara keseluruhan, perilaku karyawan yang termasuk dalam organizational citizenship.

Sementara peranan personal development competitive attitude pada manajemen konflik solution-orientation diketahui lebih rendah dibandingkan organizational citizenship behavior. Hal tersebut dikarenakan individu dapat menerapkan manajemen konflik solution-orientation karena memiliki persepsi yang positif terhadap konflik antar rekan kerja serta diiringi dengan kemampuan dalam menangani konflik secara individual. Hal tersebut dapat dikarenakan adanya faktor pada diri individu seperti high concern for selfllow concern for others versus low concern for self/high concern for others mempengaruhi kecenderungan individu untuk berbeda dalam pemilihan strategi konflik secara mandiri (Kaushal \& Kwantes, 2006). Selain itu, aspek sportmanship dalam individu memiliki karakteristik perilaku yang sama dengan individu yang memiliki personal development competitive attitude. Individu tersebut akan cenderung mengambil sisi positif dalam konflik bagi dirinya tanpa 
keluhan. Melalui pernyataan tersebut, dapat terlihat dinamika bahwa individu dapat menerapkan manajemen konflik yang beragam dalam suatu waktu baik dengan cara yang mandiri atau kolaborasi.

Individu yang memiliki personal development competitive attitude juga didapati memiliki kemampuan memperlakukan orang lain dengan baik (Ryckman, 2008). Pernyataan tersebut mengindikasikan bahwa individu cenderung memiliki relasi yang sehat dengan lingkungannya (low aggressiveness). Disisi lain pada organizational citizenship behavior yang tinggi juga membuat individu memiliki orientasi interpersonal yang positif sehingga peran organizational citizenship behavior lebih terlihat (Vieweg, 2018). Melalui penjelasan tersebut maka organizational citienship behavior memiliki peranan yang lebih besar terhadap manajemen konflik solutionorientation dibandingkan dengan personal development competitive attitude. Oleh karena itu, hipotesis mayor dinyatakan diterima.

\section{Peran PDCA terhadap manajemen konflik solution-orientation}

Pernyataan tersebut memiliki arti bahwa personal development competitive attitude memiliki peran dengan sumbangan efektif sebesar 3,5\% terhadap manajemen konflik solution-orientation. Hal tersebut dapat dikarenakan setiap individu memiliki persepsi yang berbeda-beda terkait konflik yaitu konstruktif atau destruktif (Thakore, 2013). Persepsi yang ada pada personal development competitive attitude adalah persepsi yang konstruktif. Hal ini sesuai dengan pernyataan dari Ryckman et al. (1996) bahwa individu yang memiliki personal development competitive attitude saat menghadapi tantangan selalu berfokus pada pengembangan dirinya sendiri. Hal tersebut mengindikasikan bahwa individu mampu melihat konflik sebagai peluang untuk pengembangan dirinya kearah yang positif. Sebaliknya, individu tidak akan memiliki keinginan untuk mendominasi atau memaksakan kehendak untuk menang dalam situasi tertentu. Dalam hal ini, individu akan cenderung memiliki relasi interpersonal yang positif sehingga peluang dalam penyelesaian suatu masalah dengan manajemen konflik solutionorientation cukup terlihat.

Pernyataan tersebut menjadi dasar bahwa adanya peran dari personal development competitive attitude pada manajemen konflik solution-orientation sehingga hipotesis minor satu dinyatakan diterima.

\section{Peran OCB terhadap Manajemen Konflik Solution-Orientation}

Penelitian ini membuktikan bahwa organizational citizenship behavior berperan terhadap manajemen konflik solution-orientation $\left(\mathrm{R}=0,567 ; \mathrm{R}^{2}=\right.$ $0,322 ; \mathrm{t}=6,003 ; \mathrm{p}<0,001)$. Pernyataan tersebut memiliki arti bahwa organizational citizenship behavior memiliki peranan terhadap manajemen konflik solution- orientation sebesar $32,2 \%$. Hal tersebut dapat dikarenakan manajemen konflik yang berorientasi pada solusi menekankan pada kolaborasi antar individu dalam penyelesaian masalah sehingga kemampuan untuk bekerja sama merupakan hal yang penting (Madalina, 2016) . Ketika individu memiliki tingkat organizational citizenship behavior yang tinggi maka individu tersebut cenderung menunjukkan sikap-sikap prososial yang menekankan pada kolektivisme. Salah satu bentuk nyata dari kolektivisme adalah kerjasama (Arini, 2011). Kemampuan bekerjasama tersebut dapat ditemukan dalam perilaku-perilaku yang mengarah pada organizational citizenship behavior. Hal tersebut membuat individu akan cenderung memiliki kemampuan dalam manajemen konflik solution-orientation. 
Penelitian ini juga menambahkan hasil dari korelasi antara dimensi dari organizational citizenship behavior terhadap manajemen konflik solution- orientation. Dimensi altruism merupakan salah satu dimensi yang memiliki hubungan paling kuat dengan manajemen konflik solutionorientation $(\mathrm{r}=0,538 ; \mathrm{p}<0,001)$. Penjelasan dari altruism adalah perilaku karyawan membantu orang lain secara spesifik dalam tugas yang berkaitan dengan organisasinya (Podsakoff et al.,1997). Hal ini sejalan dengan definisi yang dikemukakan oleh Van Emmerik, Jawahar, dan Stone (2005) yaitu altruism merupakan kecenderungan individu untuk memikirkan kesejahteraan orang lain dan merasa empati serta melakukan tindakan yang dapat membantu orang lain. Organisasi dengan karyawan altruistik dapat lebih mudah menciptakan iklim tempat kerja yang di mana orang akan secara sukarela bersedia membantu orang lain dengan masalah terkait pekerjaan. Adanya iklim altruism di perusahaan, akan menciptakan lingkungan pekerjaan yang sehat sehingga dapat meningkatkan kepuasan kerja karyawan hingga mampu meredakan perselisihan yang terjadi antar karyawan (Mallen, 2015) . Situasi tersebut memberikan keuntungan tidak hanya bagi karyawan namun juga perusahaan yaitu peningkatan kinerja. Kecenderungan karyawan sukarela membantu rekan lain merupakan perilaku yang menunjukkan adanya kolaborasi antar karyawan dalam menyelesaikan suatu pekerjaan atau permasalahan. Hal tersebut menjelaskan dimensi altruism menunjukkan hubungan yang lebih kuat pada dimensi organizational citizenship behavior terhadap manajemen konflik solutionorientation. Hal yang sama terlihat bahwa adanya hubungan pada dimensi conscientiousness dengan manajemen konflik solution-orientation $(\mathrm{r}=0,492 ; \mathrm{p}<$ 0,001). Conscientiousness merupakan kesadaran dari perilaku yang ditunjukkan karyawan yang melebihi batas minimum pekerjaannya. Conscientiousness juga dapat dikatakan aspek yang membuat individu berperilaku rajin dan berinisiatif dalam bekerja (Putri \& Utami, 2017). Dengan adanya aspek ini, ketika karyawan menghadapi suatu konflik atau permasalahan akan secara langsung berinisiatif untuk menangani konflik yang ada. Hal yang sama terlihat bahwa adanya hubungan pada dimensi courtesy dengan manajemen konflik solution-orientation $(\mathrm{r}$ $=0,528 ; \mathrm{p}<0,001)$. Courtesy adalah perilaku karyawan yang bertujuan untuk mencegah permasalahan yang berkaitan dengan pekerjaan. Melalui dimensi courtesy juga menunjukkan perilaku yang cenderung peduli dan mempunyai menjaga hubungan baik dengan orang lain (Putri \& Utami, 2017). Oleh karena itu ketika karyawan yang tinggi dalam courtesy ketika menghadapi suatu konflik, akan cenderung menyikapi dengan mengutamakan relasi dengan orang lain. Hal ini adalah salah satu ciri-ciri manajemen konflik solution-orientation yang menghasilkan win-win solution pada semua pihak yang terlibat. Hal yang sama terlihat bahwa adanya hubungan pada dimensi civic virtue dengan manajemen konflik solution-orientation $(\mathrm{r}=0,475 ; \mathrm{p}<$ 0,001). Civic Virtue merupakan partisipasi dan perhatian karyawan terhadap keberlanjutan perusahaan. Pada aspek ini terlihat jelas bahwa kemauan karyawan untuk berpartisipasi terkait keseluruhan agenda termasuk saat adanya konflik. Karyawan tersebut akan lebih cenderung memperhatikan kepentingan perusahaan sehingga mendorongnya untuk terlibat dalam penyelesaian konflik demi kemajuan perusahaan. Dengan adanya aspek ini, dikatakan bahwa mampu mengkolaborasikan dan mengatur kebersamaan karyawan ketika menghadapi konflik (Suzana, 2017). Oleh karena itu, aspek civic virtue memiliki hubungan dengan manajemen konflik solutionorientation.

Dimensi sportmanship memiliki hubungan yang paling rendah dibanding dimensi 
lainnya terhadap manajemen konflik solution-orientation $(r=0,228 ; \mathrm{p}=0,015)$. Sportmanship merupakan perilaku karyawan untuk mampu menoleransi perubahan yang terjadi dibawah standar tanpa komplain. Ketika karyawan berhadapan dengan konflik atau situasi tidak nyaman lainnya, ia akan cenderung berdiam diri untuk menerima keadaan. Hal ini sesuai dengan pernyataan dari Siregar (2018) bahwa seseorang yang tinggi dalam aspek sportmanship akan cenderung menahan diri untuk memprotes atau mengeluhkan keadaan yang membuat tidak nyaman. Individu yang memiliki tingkat sportmanship yang tinggi cenderung lebih fokus terhadap dirinya sendiri dalam peningkatan kerja atau pengembangan kemampuan diri yang lainnya (Siregar, 2018). Hal tersebut terjadi karena individu menilai bahwa sikap protes dan mengeluh tidak berpengaruh terhadap keadaan atau kinerjanya, sehingga akan lebih berfokus pada pengembangan dirinya. Dalam hal ini ketika individu dihadapkan pada suatu konflik yang membuat tidak nyaman, individu tersebut akan cenderung menyelesaikan konflik secara mandiri atau cenderung individualis. Hal ini dikuatkan oleh pernyataan dari Kaushal dan Kwantes (2006) bahwa individu yang memiliki fokus tinggi pada dirinya cenderung menghadapi konflik dengan cara abai atau individualis.

\section{SIMPULAN}

Berdasarkan hasil dari penelitian yang telah dilakukan, diperoleh kesimpulan terdapat sumbangan efektif sebesar $35,7 \%$ pada peran personal development competitive attitude dan organizational citizenship behavior terhadap manajemen konflik solution- orientation pada karyawan EO. Organizational citizenship behavior memiliki sumbangan efektif yang lebih besar yaitu 32,2\%, hal ini dikarenakan kontribusi sikap yang menunjukkan altruism memiliki hubungan yang kuat dengan manajemen konflik solution- orientation. Dengan adanya perilaku altruism yaitu kecenderungan individu untuk berempati dan membantu orang lain akan dapat meredakan perselisihan yang terjadi. Hal ini membuktikan ada kecenderungan karyawan untuk berkolaborasi dalam mengatasi suatu permasalahan dalam pekerjaan. Sedangkan untuk personal development competitive attitude, memiliki peran yang jauh lebih rendah yaitu $3,5 \%$. Hal tersebut dikarenakan individu yang tinggi dalam faktor ini cenderung menggunakan manajemen konflik yang individualis atau mendominasi meskipun memiliki relasi interpersonal yang baik terhadap sekitarnya namun masih membuka peluang untuk menerapkan manajemen konflik solution-orientation (kolaborasi solusi). Oleh karena itu, hipotesis mayor dan minor diterima.

\section{DAFTAR PUSTAKA}

Anwar, K. (2018). Penerapan manajemen konflik dalam organisasi. Jurnal Studi dan Penelitian Pendidikan Islam, 1(2), 31-38.

Arikunto, S. (2013). Prosedur penelitian. Jakarta: Rineka Cipta

Arini, D. W. (2011). Hubungan antara perilaku kewargaan organisasional dan kinerja tugas. Jurnal Manajemen Teori dan Terapan, 4(1), 73-86.

Basuki, A. T., \& Prawoto, N. (2016). Analisis regresi dalam penelitian ekonomi \& bisnis: Dilengkapi aplikasi SPPS \& EVIEWS. Depok: PT Rajagrafindo Persada.

Brahmasari, I. A. (2009). Organizational Citizenship Behavior (OCB) dan Isu Gender. Jurnal Ilmu Ekonomi dan Manajemen, 5(2), 81-104.

Dalimunthe, I., Absah, Y., \& Salim, S. R. (2017). The effect of interpersonal relationships and role ambiguity on job 
satisfaction and its impact toward employees' intention to leave in event organizer services provider in Medan. Advances in Economics, Business and Management Research (AEBMR), 46(1), 346-352.

Kaushal, R., \& Kwantes, C. T. (2006). The role of culture and personality in choice of conflict management strategy. International Journal of Intercultural Relations, 30(5), 579- 603. DOI: 10.1016/j.ijintrel.2006.01.001

Kompas.com. (2020, Februari 3). 7 cara mudah mengatasi stres kerja. Berita Kompas. Diunduh di https://health.kompas.com/read/2020/ 02/03/073300368/7-cara-mudahmengatasi-stres-kerja?page $=$ all, tanggal 20 Maret 2020.

Larson, M. (2001). Organizing events: Managing conflict and consensus in a political market square. Event Management, 7, 51-65.

Lievens, F., \& Anseel, F. (2004). Confirmatory factor analysis and invariance of an organizational citizenship behaviour measure across samples in a dutch-speaking context. Journal of Occupational and Organizational Psychology, 77(3), 299-306. DOI: $10.1348 / 0963179041752727$.

Madalina, O. (2016). Conflict management, a new challenge. Procedia Economics and Finance, 39, 807-814.

Mallen, J. (2015). The effects of altruism and relationship conflict on organizational learning. Jornal of a Conflict Management, 26(1), 85-112. DOI: 10.1108/IJCMA-12-2013-0100.

Manurung, M. Y. (2020, Januari 16). Kasus penyekapan di Pulomas, Polisi: Konflik internal perusahaan. Metro Tempo. Diunduh https://metro.tempo.co/read/1295678/ kasus-penyekapan-di-pulomas-polisikonflik-internal-perusahaan, tanggal November 2020.

Podsakoff, P. M., MacKenzie, S. B., Moorman, R. H., \& Fetter, R. (1990). Transformational leader behaviors and their effect on followers trust in leader, satisfaction, and organizational citizenship behaviors. Leadership Quarterly, 1(2), 107-142.

Putnam, L. L., \& Wilson, C. E. (1982). Communicative strategies in organizational conflicts: Reliability and validity od a measurement scale. Annals of the International Communication Association, 6(1), 629-652. DOI: 10.1080/23808985.1982.11678515.

Putri, Y. D., \& Utami, H. N. (2017). Pengaruh organizational citizenship behavior (OCB) terhadap kinerja (studi pada tenaga perawat ruang rawat inap Rumah Sakit Baptis Batu). Jurnal Administrasi Bisnis, 46(1), 27-34.

Rusdiana, A. (2015). Manajemen konflik. Bandung: Pustaka Setia.

Ryckman, R. M. (2008). Theories of personality. Belmont, CA: Thomson Wadsworth.

Ryckman, R. M., Hammer, M., Kaczor, L. M., \& Gold, J. A. (1996). Construction of a personal development competitive attitude scale. Journal of Personality Assessment, 66(2), 374-385. DOI: 10.1207/s15327752jpa6602_15.

Ryckman, R., Hammer, M., Kaczor, L., \& Gold, J. (1990). Construction of a hypercompetitive attitude scale. Journal of Personality Assessment, 55(3-4), $\quad$ 630$639 . \quad$ DOI: 10.1207/s15327752jpa5503\&4_19. 
Siregar, B.G. (2018). Organizational citizenship behavior dan kinerja akademis mahasiswa. FITRAH Jurnal Kajian IlmuIlmu Keislaman, 4(1), 29-42. E-ISSN : 2406-2345, p-ISSN: 2442-6997

Sulistyaningrum, D. (2012). Pengaruh brand loyalty terhadap variety seeking. Journal of Social and Industrial Psychology, 1(2), 41-46.

Suzana, A. (2017). Pengaruh organizational citizenship behavior (OCB) terhadap kinerja karyawan (studi di: PT. Taspen (Persero) kantor cabang Cirebon). LOGIKA Jurnal Ilmiah Lemlit Unswagati Cirebon, 19(1), 42-50.

Thakore, D. (2013). Conflict and conflict management. Journal of Business and Management, 8(6), 7-16. e-ISSN: 2278487X.

Van Emmerik, I., Jawahar, I., \& Stone, T. (2005). Associations among altruism, burnout dimensions, and organizational citizenship behavior. Work \& Stress, 19(1), 93-100.

Vieweg, J. C. (2018). Prosocial behaviors: Their motivations and impacts on organizational culture. The Journal of Values-Based Leadership, 11(2), 12.

Widiyanto, G. (2018). Perilaku individu dalam menghadapi konflik \& pengaruhnya terhadap kinerja organisasi. Jurnal Ekonomi dan Bisnis, 16(1), 70-88. DOI: 10.31253/pe.v16i1.57. 